\title{
Patient evaluations of asthma counselling quality in primary health care - a cross-sectional survey
}

\author{
Katariina Mäkelä ${ }^{1}$ - Mira Rajala ${ }^{2} \cdot$ Kirsi Kivelä $^{3} \cdot$ Maria Kääriäinen $^{4} \cdot$ Pirjo Kaakinen $^{5}$ (D)
}

Received: 29 January 2020 / Accepted: 27 March 2020 / Published online: 20 April 2020

(C) The Author(s) 2020

\begin{abstract}
Background Healthcare staff have a key role in counselling patients. This study describes asthma patients' evaluations of primary care counselling quality.

Methods The research applied a cross-sectional study design, with data collected from adult asthma patients $(n=73)$. Data were analysed by descriptive statistics.

Results Most of participating patients were women (73\%) and over 60 years old (67\%). The patients were generally satisfied with the counselling. Subjection to an asthma test $(p=0.009)$ and smoking $(p=0.019)$ were found to significantly positively affect patient perceptions of counselling quality. The patients also felt that support services should be covered more (74\%). Patients with comprehensive education $(p=0.039)$ and smokers $(p=0.015)$ were more likely to be satisfied with the counselling than other patients. Counselling was client-oriented (53\%) and most patients reported experiencing positive interactions (92\%). Most patients agreed that counselling benefitted adherence to self-care (75\%) and health promotion (67\%). Moreover, almost all of the patients were satisfied with the staff members' knowledge and skills (97\%). Subjection to an asthma test $(p=0.043)$, age $(p=$ $0.030)$, smoking $(p=0.014)$, and duration of illness $(p=0.002)$ influenced satisfaction with counselling resources.

Conclusion The results indicate that counselling benefits asthma patients. Performing an asthma test, as well as considering smoking habits and educational level, can improve patient perceptions of counselling.
\end{abstract}

Keywords Asthma $\cdot$ Counselling $\cdot$ Education $\cdot$ Quality of counselling $\cdot$ Primary healthcare

Pirjo Kaakinen

pirjo.kaakinen@oulu.fi

Mira Rajala

mira.rajala@oulu.fi

Kirsi Kivelä

kirsi.kivela@ouka.fi

Maria Kääriäinen

maria.kaariainen@oulu.fi

1 City of Oulu, Finland

2 Research Unit of Nursing Science and Health Management, Finland Medical Research Center, University of Oulu, Oulu, Finland

3 Health Services, City of Oulu, Finland

4 Research Unit of Nursing Science and Health Management, Finland, Medical Research Center, University Hospital of Oulu, University of Oulu, Oulu, Finland

5 Research Unit of Nursing Science and Health Management, University of Oulu, Oulu, Finland

\section{Introduction}

Asthma is an inflammatory and chronic disease, with an incidence of about $10 \%$ among the Finnish adult population (THL 2017). Furthermore, according to WHO (2018), approximately 235 million people around the world are afflicted by asthma. In Finland, adults with asthma are predominantly treated in primary care. The current model of asthma control focuses on counselling for self-care, progressing towards wellcontrolled asthma through the Asthma Control Test (ACT), checking inhaler technique, and providing written instructions for home care (Gibson 2009; Asthma Guideline 2012; Haahtela et al. 2017; Schuermans et al. 2018). Finnish patients with asthma have the right to receive the healthcare support that their medical condition requires, and have come to expect high-quality healthcare. According to Finnish law, patients also have the opportunity to take part in the decision-making regarding their care (Act 1992/785). In primary care, nurses have an active role in the follow-up phase of asthma care, along with the assessment of a patient's health status. It is also 
known that uncontrolled asthma increases healthcare costs and hospital admissions relative to controlled asthma (Nunes et al. 2017).

Counselling is based on the patients' needs and, as such, the healthcare staff's background and competence are key factors in determining counselling quality. For example, well-trained staff will know that goal-oriented and preplanned counselling provide a good start to counselling. Furthermore, successful counselling requires active interaction between the patient and healthcare staff. Only a few studies have investigated counselling from the viewpoint of an asthma patient (Lingner et al. 2017), with most of the previous research focusing on counselling interventions (e.g., Clark et al. 2010) or self-care (e.g., Gibson et al. 2009). This study examines adult asthma patients' perceptions of counselling quality, with the quality of counselling described based on the content, implementation, and benefits of counselling, along with the available resources for counselling. This study also examines the quality of counselling for adult clients with asthma; the quality of counselling is defined as a sufficient content of counselling, implementation and counselling resources are adequate, and counselling have benefit for clients (Kääriäinen 2007; Kivelä et al. 2014; Kaakinen et al. 2017).

Asthma patients need counselling about asthma as a disease and about its symptoms (Jing et al. 2012; Kaakinen et al. 2017; Murray \& O’Neill 2018). In order to be effective, asthma counselling should focus on medication, more specifically, safe dosage and correct inhalation technique (Kauppi et al. 2015; Lee et al. 2016). However, there is a general lack of inhalation technique counselling (Kauppi et al. 2015; Lingner et al. 2017), and worryingly, Hickey (2014) reports that there is also a lack of staff who are able to demonstrate the correct inhalation technique. Patients are used to taking medication and immediately experiencing a degree of relief in their symptoms. However, healthcare professionals should focus on counselling asthma patients about how lifestyle, e.g., physical activity and smoking, influences asthma symptoms (Lingner et al. 2017). For example, it is well known that smoking (Murray \& O'Neill 2018) and high BMI (Wright et al. 2010) increase the risk of experiencing asthma attacks. Furthermore, previous research has shown that asthma patients desire social support, for example how they can find peer support for managing day-to-day activities (Kääriäinen 2007; Kaakinen et al., 2013). Asthma symptoms are predominantly treated through an inhaled medicine, but previous research has shown that certain patients inhale the medication incorrectly (Maricoto et al. 2015; Sanchis et al. 2016; Lavorini et al. 2008). Hence, counselling must cover inhalation technique if the objective is to move towards well-controlled asthma. Based on that, a good counselling on inhalation technique is essential for good asthma balance.

Patient-centred counselling is an approach that focuses on individual patient needs (Goeman et al. 2013; Raitanen et al. 2015; Murray \& O'Neill 2018) and is implemented in a way that considers the patient's cultural background (Purnell 2014). This type of counselling allows patients to discuss their treatment and how to manage asthma disease with healthcare staff (Raitanen et al. 2015; Gagne et al. 2017). It is important to note that patients are generally more satisfied with the counselling if it is performed in a confidential manner (Clark et al. 2010; Kääriäinen \& Kyngäs 2010; Lee et al. 2016). Throughout the counselling process, healthcare staff should interact with, and observe, patients to identify the best approach for educating the patient about how to manage with asthma (Kääriäinen \& Kyngäs 2010; Raitanen et al. 2015). Furthermore, healthcare staff should keep in mind that asthma may cause distress to the patient - either through asthma attacks or medication (Lingner et al. 2017). This is additional evidence of why good counselling is important for asthma patients. Even though a patient may have used inhaled medication for years, healthcare staff should nevertheless periodically check that the patient knows the correct inhalation technique (Jha et al. 2016).

High-quality counselling has many benefits for asthma patients. It helps clients make correct decisions (Gagne et al. 2017) and have a positive attitude towards both the disease and adherence to care (Kääriäinen 2007; Clark et al. 2010; Pallasaho \& Pietinalho 2018; Oikarinen et al. 2017). Furthermore, high-quality counselling can positively influence the patient's quality of life and asthma control (Gibson et al. 2009; Agbetile \& Green 2011; Schuermans et al. 2018). In counselling, patients are always the expert when it comes to their own life, and counselling which takes into account the client's life situation will help achieve the treatment goals (Rajala et al. 2018). The quality of asthma counselling has also been shown to reduce the cost of care (Haahtela et al. 2017; Maricoto et al. 2019) and amount of sick leave (Haahtela et al. 2017).

In addition to healthcare staff competence, the quality of counselling depends on resources, such as counselling time, counselling materials, and education for staff members (Kääriäinen 2007; Kaakinen 2013; Raitanen et al. 2015). Some of these resources should be allotted to the continuous education of staff, as healthcare staff need to be trained in interaction skills (Lamiani \& Furey 2009) and client-centred counselling (Kaakinen et al. 2013), both of which they have not learned during their academic education. Asthma counselling is still generally provided verbally, with written instructions only used to support verbal counselling (Rajala et al. 2018). Demonstration(Press et al. 2012) and technology-supported counselling is not used as often as possible, even if technology is known to provide additional benefits to counselling (Bartlett \& Coulson 2011; Wilson et al. 2010; Pool et al. 2017; Jin et al. 2019). 


\section{Aim of the study}

The present study aimed to describe asthma patients' evaluations of the quality of counselling they received in primary care, as well as identify factors which influence the quality of counselling.

\section{Methods}

\section{Survey design and setting}

The present research employed a cross-sectional study design, with the data collected from September 2018 to January 2019. The survey was conducted in collaboration with a primary care organisation in northern Finland, and the study received approval from the primary care organisation.

\section{Participants and data collection}

The study participants were adults over 18 years of age who had been diagnosed with asthma $(n=170)$. background information is shown in Table 1 below. Patients who had a health check-up scheduled at the primary care centre during the data collection period were eligible to participate in the survey. The patients had an opportunity to answer the questionnaire after their health check-up, and were instructed to return it in a sealed envelope to a designated closed box in reception or to one of the researchers via post. All of the patients were informed that taking part in the study was voluntary, and answering the questionnaire was interpreted as consent to participate in the research. Moreover, all of the patients received a cover letter which included information about the aim of the study, and contact details for the main researcher.

Data were collected using the Counselling Quality Instrument (CQI), which was developed to determine the quality of patient counselling (@ Kääriäinen 2009.) Previous studies have determined that the CQI shows adequate internal consistency and structural validity (Kaakinen et al. 2017, Rajala et al. 2018). The instrument includes ten background questions, while the quality of counselling is determined based on four dimensions: content of counselling (18 items), implementation of counselling (33 items), benefits of counseling (17 items), and resources for counselling (ten items). Respondents score each item related to the quality of counselling using a five-point Likert scale ( $5=$ totally agree, $1=$ totally disagree). Furthermore, the instrument includes one openended question about the development of counselling. The instrument developer modified the content of the instrument to fit the study group. Instrument content validity was tested by three asthma nurses, and based on their assessment, two items were deleted.

\section{Data analysis}

Data were analysed by SPSS Statistics for Windows (version 25.0, IBM Corp., Armonk, NY, USA). Descriptive statistics were used to calculate the frequencies and percentages of patient satisfaction with counselling. Quality of counselling sum variables were identified by factor analysis (Varimax). Sum variables were named based on the content. More specifically, content of counselling included three sum variables: "knowledge of disease and its treatment", "supportive services", and "health promotion". Implementation of counselling included three sum variables: "client-centred counselling", "interaction of counselling", and "atmosphere of counselling". Benefits of counselling included two sum variables - "adherence to care" and "benefits of health promotion" - while resources for counselling included one sum variable "staff knowledge and skills" (Table 2).

The communalities for sum variables identified through factor analysis varied from 0.27-0.89, while the Cronbach's alpha values for the same sum variables ranged from $0.75-0.95$ (Table 2). Each sum variable was differentiated into two categories based on the histogram: scores of 1.00-2.50 described satisfactory counselling, while scores between 2.51-5.00 described unsatisfactory counselling. Relationships between background and sum variables were assessed using the Fisher's $\chi^{2}$ test and $t$ test in cases with normal distribution, while the MannWhitney U-test and the Kruskal-Wallis test were used in other cases. The threshold for statistical significance was set at $p<0.05$ (Polit \& Beck 2012).

\section{Results}

The present study achieved a response rate of $43 \%$, and background information (e.g., age and marital status) for the participants $(n=73)$ is presented in Table 1 . Most of the patients were women (73\%), and over half $(61 \%)$ were 60 years of age or older. The participants predominantly lived in couples' households (68\%), and almost half held a university degree (48\%). Half of the participants $(52 \%)$ had been afflicted by asthma for under 10 years, with $14 \%$ of the participants in this subgroup identifying as smokers. According to the participants, the counselling predominantly included an individual focus (95\%), assessment of asthma control through ACT (82\%), and a check of proper inhalation technique via the PIF test (92\%). Two-thirds of the patients $(65 \%)$ did not have a written asthma follow-up card. Patients with a university education were more likely to have a written asthma follow-up card than patients with a comprehensive education $(p=0.035)$. 
Table 1 Background information of clients $(n=73)$

\section{Content of counselling}

Content of counselling included knowledge of the disease and its treatment, supportive services, and health promotion (Table 2). Most of the participants (82\%) agreed that they were satisfied with counselling concerning the disease and its treatment. Satisfaction with this type of counselling was found to be significantly affected by being subjected to an asthma test $(p=0.009)$ and by smoking $(p=0.019)$. A noticeable proportion of the participants (26\%) identified a lack of counselling in supportive services. However, patients who had been subjected to an asthma test $(p=0.032)$, patients with a comprehensive education $(p=0.039)$, and smokers $(p=0.014)$ were more likely to be satisfied with counselling of supportive services than other patients. A majority of the patients (59\%) were also satisfied with the counselling for health promotion. Statistical analyses revealed that education $(p=0.05)$ and subjection to an asthma test $(p=0.018)$ affected satisfaction with counselling of health promotion, as patients with a comprehensive education and patients who had been subjected to an asthma test were more satisfied with this counselling than other patients.

\section{Implementation of counselling}

Implementation of counselling included client-centred counselling, interaction during counselling, and atmosphere of counselling (Table 2). Half of the participants (53\%) felt that they had received patient-centred counselling during their primary care visits, while a clear majority $(92 \%)$ were satisfied with the interaction during counselling (Table 2). Perceptions of client-centred counselling were found to be significantly affected by whether the patient had been subjected to an asthma test $(p=0.015)$. Most of the patients $(89 \%)$ were satisfied with the atmosphere they experienced during counselling. However, smoking $(p=0.042)$ significantly affected satisfaction with atmosphere, as smokers were more satisfied with the atmosphere they experienced than non-smokers.

\section{Benefits of counselling}

Benefits of counselling included adherence to self-care and health promotion (Table 2). Importantly, patients reported counselling to have a positive impact on their adherence to care $(75 \%)$ and health promotion $(67 \%)$ respectively However, a third (33\%) of the patients reported feeling that counselling will not benefit their health promotion.

\section{Resources for counselling}

Resources for counselling included staff knowledge and skills (Table 2). The asthma patients were satisfied with the staff members' knowledge (94\%) and skills (97\%). Patients who were subjected to an ACT during counselling $(p=0.043)$, were 20-39-years old $(p=0.030)$, smoked $(p=0.014)$, and had been afflicted by asthma for under 10 years $(p=0.002)$ were more likely to be satisfied with staff members' knowledge and skills than other patients.

\section{Discussion}

This study aimed to describe adult asthma patients' assessments of the quality of counselling received at primary care, as well as explain factors related to satisfaction with counselling. Based on the presented results, asthma patients were generally content with the quality of counselling in primary 
Table 2 Sum variables, number of items, total variance, Cronbach's alpha, and quality of counselling based on sum variables

\begin{tabular}{llllll}
\hline Sum variables name & $\begin{array}{l}\text { Number of } \\
\text { items }\end{array}$ & $\begin{array}{l}\text { Total } \\
\text { variance } \%\end{array}$ & $\begin{array}{l}\text { Cronbach } \\
\text { alpha }\end{array}$ & $\begin{array}{l}\text { Good } \\
\%\end{array}$ & $\begin{array}{l}\text { Poor } \\
\%\end{array}$ \\
\hline $\begin{array}{l}\text { Content of counselling } \\
\begin{array}{l}\text { Knowledge of disease and its } \\
\text { treatment }\end{array}\end{array}$ & 17 & 59.3 & 0.92 & 82 & 18 \\
$\begin{array}{l}\text { Support services } \\
\text { Health promotion }\end{array}$ & 5 & 68.2 & 0.90 & 26 & 74 \\
$\begin{array}{l}\text { Implementation of counselling } \\
\text { Client-centered counselling }\end{array}$ & 5 & 74.9 & 0.91 & 59 & 41 \\
Interaction during counselling & 15 & & & & \\
Atmosphere of counselling & 7 & 45.1 & 0.93 & 53 & 47 \\
Benefit of counselling & 17 & 55.9 & 0.90 & 92 & 8 \\
Adherence of care & 12 & 63.3 & 0.88 & 89 & 11 \\
Impact of health promotion & 5 & 63.1 & 0.95 & 75 & 25 \\
Counselling resources & 10 & 73.3 & 0.91 & 67 & 33 \\
Staff knowledge & 6 & 46.4 & 0.75 & 94 & 6 \\
Skills & 4 & 62.6 & 0.78 & 97 & 3 \\
\hline
\end{tabular}

care. Factors that affected patient satisfaction with counselling included being subjected to an asthma test during counselling, and smoking habits. Also, patient age, education level, and duration of disease were found to be related to satisfaction with counselling. All of these results are supported by what has been reported in earlier studies (Raitanen et al. 2015; Gibson et al. 2017). The presented results identified certain areas of counselling that should be improved, for example information about supportive services such as financial support and peer support groups. Additionally, subjecting a patient to an asthma test was found to significantly influence satisfaction with counselling among the respondents of this study and, as such, should be studied further both in Finland and international contexts. This type of research is important from patient and societal perspectives, as high-quality counselling has been shown to reduce hospital admissions (Gagne et al. 2017) and improve lung function (Gibson et al. 2009) among asthma patients.

The participating asthma patients were satisfied with the information about the disease and its treatment that they received during primary care counselling. More specifically, patients were satisfied with counselling that discussed asthma and its features, medication, and how to manage symptoms; this agrees with research by Lee et al. (2016), who reported that counselling improves patients' knowledge of the disease and inhalation technique. Lingner et al. (2017) reported contrasting findings, namely that patients were unsatisfied with counselling time and felt that they were not treated as an expert in their own asthma disease. Therefore, patients should always be afforded ample time to discuss their problems and be motivated to care for themselves. In this study, smokers were satisfied with counselling. It may be that these patients received individualised counselling and had more time to interact with staff because it is known that smoking may cause asthma attacks. Previous research has found asthma counselling to be lacking in terms of information about physical activity (Lingner et al. 2017; Winders et al. 2019), weight control, and smoking (Lingner et al. 2017). This could be explained by the counsellor asking the patient about their smoking habits at the start of counselling, and then, based on this information, deciding to spend more time educating the patient about the dangers of smoking and motivating them to make lifestyle changes. This, however, would not explain why educational level influenced satisfaction with counselling.

Based on the results, asthma patients need counselling that focuses more on supportive services. According to earlier research, patient knowledge of supportive services improves both their satisfaction with counselling (Kaakinen et al. 2012; Kaakinen et al. 2013) and adherence to care (Press et al. 2012). It is also important to state that most of the patients participating in this study did not have their asthma follow-up card, even though it is known to improve asthma control (Gibson et al. 2009).

Patients in this study were satisfied with the patient-centred counselling, as has been shown in earlier research (Rajala et al. 2018). More specifically, previous studies have proposed that patient-centred counselling supports patient decisionmaking (Gagne et al. 2017) and promotes the selfmanagement of asthma (Rajala et al. 2018). In this study, patients who had been subjected to an asthma test were more likely to be satisfied with counselling. It could be expected that patients who were subjected to this test felt that the counselling was more individualised and patient-centred than 
patients who had not been offered the test, and thus, would be more satisfied with the experience. The participating patients also appreciated interaction with the healthcare professional, as this allowed them the opportunity to ask questions that they felt were important. A positive atmosphere was also found to be conducive to discussions with healthcare professionals, a finding which is supported by earlier research (Lingner et al. 2017; Rajala et al. 2018). In these situations, it is likely that the patients felt that they were being listened to and treated as experts in living with asthma. High-quality counselling is also related to adherence to care (Raitanen et al. 2015; Clark et al. 2010; Pallasaho \& Pietinalho 2018). In this study, asthma patients felt that counselling complemented their knowledge of asthma and how to treat it at home. This study identified many benefits of counselling, with the participating patients expressing a more positive view of adherence to care following counselling (75\%) than was reported in the study by Kaakinen et al. (2017).

Based on earlier studies (Kääriäinen 2007; Kaakinen 2013; Raitanen et al. 2015), resources for counselling comprise staff members' knowledge and healthcare organisation resources. We found that patients under the age of 40 and patients who had been afflicted by asthma for under 10 years were satisfied with staff members' knowledge, while other patients were not satisfied with this aspect of counselling. According to Miedinger et al. (2011), the use of an asthma test improves staff members' abilities to assess disease control and also promotes asthma control among patients. Currently, the PIF instrument is commonly used to check inhalation technique; however, according to the presented results and previous research, other methods - such as internet videos - are not widely used in counselling (Rajala et al. 2018). A metaanalysis by Maricoto et al. (2018) found that video demonstrations of proper inhalation technique can promote positive habits among patients. Therefore, primary care counselling should focus on using various techniques to ensure good inhalation technique among patients. Additionally, Pool et al. (2017) found that online reminders regarding asthma care positively affected patients' asthma control.

\section{Limitations and strengths}

One limitation is that the participating patients are only representative of a single primary care organisation. A second limitation is the low response rate. The response rate may have been affected by the length of the questionnaire (a total of 78 items), which may be too long for some patients. Researchers who perform voluntary surveys should question how motivated the study population is to take part in the study and answer the questionnaire. For example, although the asthma patients had the opportunity to fill in the questionnaire at home, it is likely that most would ultimately not return it to the researcher.
In terms of strengths, this study applied a questionnaire (QCI) which showed adequate content validity in this study, and which has shown good content validity in numerous prior studies (Kääriäinen 2007; Kääriäinen \& Kyngäs 2010; Kaakinen et al. 2013; Kaakinen et al. 2017; Rajala et al. 2018 The questionnaire was modified for the target group, and tested with three nurses who were specialised in asthma care. The Cronbach's alpha values for the various sum variables ranged from $0.75-0.95$, which provides evidence for instrument validity (Polit \& Beck 2012). Instrument validity was also tested through factor analysis and by having expert nurses evaluate the content of the questionnaire. However, because the response rate was low and the presented findings only represent one primary care organisation, the conclusions drawn from this study are not generalizable to other contexts.

\section{Conclusion}

Healthcare staff have an essential role in counselling patients and, as such, should take into account individual patient needs when counselling asthma patients. The presented research found subjection to an asthma test and smoking habits to significantly positively impact patient satisfaction with the provided primary care counselling. Furthermore, numerous patients felt that supportive services should be covered, more during their counselling sessions. The conclusions drawn from the presented analyses are relevant because highquality counselling of asthma patients improves patient adherence to care and promotes healthy behaviours, both of which translate to decreased healthcare costs.

Funding Information Open access funding provided by University of Oulu including Oulu University Hospital. The authors did not receive financial support for this research.

\section{Compliance with ethical standards}

Conflict of interest The authors declared no potential conflicts of interest with respect to the research publication of this article.

Informed consent Informed consent was collected from every participating patient.

Open Access This article is licensed under a Creative Commons Attribution 4.0 International License, which permits use, sharing, adaptation, distribution and reproduction in any medium or format, as long as you give appropriate credit to the original author(s) and the source, provide a link to the Creative Commons licence, and indicate if changes were made. The images or other third party material in this article are included in the article's Creative Commons licence, unless indicated otherwise in a credit line to the material. If material is not included in the article's Creative Commons licence and your intended use is not permitted by statutory regulation or exceeds the permitted use, you will need to obtain permission directly from the copyright holder. To view a copy of this licence, visit http://creativecommons.org/licenses/by/4.0/. 


\section{References}

Act on the Status and Right of Patients (1992/785). https://www.finlex.fi/ en/laki/kaannokset/1992/en19920785_20120690.pdf. Accessed 29 Jan 2020

Agbetile J, Green R (2011) New therapies and management strategies in the treatment of asthma: patient-focused developments. J Asthma Allergy 4:1-2

Asthma Guideline (2012). https://www.kaypahoito.fi/en/ccs00016. Accessed 292020

Bartlett YK, Coulson NS (2011) An investigation into the empowerment effects of using online support groups and how this affects health professional/patient communication. Patient Educ Couns 83(1): 113-119

Clark NM, Griffitsh C, Keteyian SR, Partridge MR (2010) Educational and behavioral interventions for asthma: who achieves which outcomes? A systematic review. J Asthma Allergy 3:187-197

Gagne ME, Legare F, Moisan J, Boulet LP (2017) Impact of adding a decision aid to patient education in adults with asthma: a randomized clinical trial. PLoS One 20(1):2-16

Gibson PG, Powell H, Wilson A, Abrahamson MJ, Haywood P, Bauman A, Hensley MJ, Walters EH, Roberts JJL (2009) Self-management education and regular practitioner review for adults with asthma (Review). Cochrane Databases of Systematic Reviews 3: CD001117

Goeman D, Jenkins C, Crane M, Paul E, Douglass J (2013) Educational intervention for older people with asthma: a randomized controller trial. Patient Educ Couns 93(3):586-595. https://doi.org/10.1016/j. pec.2013.08.014

Haahtela T, Valovirta E, Bousquet J, Mäkelä M (2017) The Finnish allergy programme 2008-2018 works. Eur Respir J 49:1700470. https:// doi.org/10.1183/13993003.00470-2017

Hickey S (2014) Understanding the impact of inhaler technique on asthma and COPD. Nurse Prescribing 12(10):492-496

Jha T, Sahai AK, Sarkar M, Kaundal PK, Bhardwaj P, Sharma I (2016) Assessment of inhalation technique and predictors of incorrect performance among patients of chronic obstructive pulmonary disease and asthma. Int J Basic Clin Pharmacol 5(4):1598-1605. https://doi. org/10.18203/2319-2003.ijbcp20162479

Jin K, Khonsari S, Gallagher R, Gallangher P, Clark AM, Freedman B, Briffa T, Bauman A, Redfern J, Neubeck L (2019) Telehealth interventions for the secondary prevention of coronary heart disease: a systematic review and meta-analysis. Eur J Cardiovasc Nurs 18(4): 260-271

Jing-YU J-XC, Xiang-Liang L, Zhang Q, Zhang M, Li-Juan M, Lin R (2012) Meta-analysis on the impact of disease-specific education programs on health outcomes for patients with chronic obstructive pulmonary disease. Geriatr Nurs 33(4):280-296

Kaakinen P, Kääriäinen M, Kyngäs H (2013) Predictors of good-quality counseling from the perspective of hospitalized chronically ill adults. J Clin Nurs 22(19-20):2704-2713

Kaakinen P, Ervasti H, Kääriäinen M (2017) Quality of counselling for knee and shoulder arthroscopy patients during day surgery. Int $\mathrm{J}$ Orthop Trauma Nurs 24(9):12-20

Kääriäinen M (2007) The quality of counselling: The development of a hypothetical model [in Finnish]. Acta Universitatis Ouluensis D 937, 2007. University of Oulu, Oulu, Finland

Kääriäinen M, Kyngäs H (2010) The quality of patient education evaluated by the health personnel. Scand J Caring Sci 24:548-556

Kauppi P, Peura S, Salimäki J, Järvenpää S, Linna M, Haahtela T (2015) Reduced severity and improved control of self-reported asthma in Finland during 2001-2010. Asia Pac Allergy 5(1):32-39

Kivelä K, Elo S, Kyngäs H, Kääriäinen M (2014) The effects of health coaching on adult patients with chronic diseases: a systematic review. Patient Couns Educ 97(29):147-157
Lamiani G, Furey A (2009) Teaching nurses how to teach: an evaluation of a workshop on patient education. Patient Educ Couns 75(2):270 273

Lavorini F, Magnan A, Dubus JC, Voshaar T, Corbetta L, Broeders M, Dekhuijzen R, Sanchis J, Viejo JL, Barnes P, Corrigan C, Levy M, Crompton GK (2008) Effect of incorrect use of dry powder inhalers on management of patients with asthma and COPD. Respir Med 102(4):593-604

Lee JY, Yoo KH, Kim DK, Kim SH, Kim TE, Kim TH, Rhee CK, Park YB, Yoon HK, Yum H-K (2016) Effect of educational interventions for chronic airway disease on primary care. J Korean Med Sci 31: 1069-1074

Lingner H, Burger B, Kardos P, Criee CP, Worth H, Hummers-Pradier E (2017) What patients really think about asthma guidelines: barriers to guideline implementation from the patients' perspective. BMC Pulmonary Medicine 17(13):1-12

Maricoto T, Rodrigues LV, Teixeira G, Valente C, Andrade L, Saraiva A (2015) Assessment of inhalation technique in clinical and functional control of asthma and chronic obstructive pulmonary disease. Acta Medica Port 28(6):702-707

Maricoto T, Monteiro L, Gama JMR, Correia-de-Sousa J, Taborda-Barata L (2018) Inhaler technique education and exacerbation risk in older adults with asthma or chronic obstructive pulmonary disease: a meta-analysis. J Am Geriatr Soc 67(1):57-66

Maricoto T, Marques-Gomes J, Correia-de-Sousa J, Taborda-Barata L (2019) Inhaler review in older adults with asthma or COPD: a cost-effectiveness study and a perspective in Portugal. J Am Geriatr Soc 67:1430-1436

Miedinger D, Neukomn E, Chhajed PN, Schyder A, Naef M, Ackerman M, Leuppi JD (2011) The use of asthma control test in general practice and its correlation with asthma control according to the GINA guidelines. Curr Med Res Opin 27(12):2301-2308

Murray B, O’Neill M (2018) Supporting self-management of asthma through patient education. Br J Nurs 27(7):396-401

Nunes C, Pereira AM, Morais-Almeida M (2017) Asthma costs and social impact. Asthma Res Prac 3:1-11. https://doi.org/10.1186/ s40733-016-0029-3

Oikarinen A, Engblom J, Kyngäs H, Kääriäinen M (2017) Lifestyle counseling intervention effects on counseling quality in stroke and TIA patients. J Neurosci Nurs 49(3):137-141

Pallasaho P, Pietinalho A (2018) Diagnosis and treatment of asthma in adults in primary health care. Lääkärilehti 6(73):353-357 Abstract in English

Polit DF, Beck CT (2012) Nursing research: generating and assessing evidence for nursing practice. Wolters Kluwer Health/Lippincott Williams \& Wilkins, Philadelphia

Pool AC, Kraschnewski JL, Poger JM, Smyth J, Stuckey HL, Craig TJ, Lehman E, Yang C, Sciamanna N (2017) Impact of online patient reminders to improve asthma care: a randomized controlled trial. PLoS One 12(2):1-17

Press V, Arora V, Shah L, Lewis S, Charbenau J, Naureckas E, Krishnan J (2012) Teaching the use of respiratory inhalers to hospitalized patients with asthma or COPD: a randomized trial. J Gen Intern Med 27(10): 1317-1325

Purnell LD (2014) Guide to culturally competent health care, 3rd edn. FA Davis Company, Philadelphia

Raitanen K, Kylmä J, Paavilainen E (2015) Short term patient and family counselling for acute health change - an integrative literature review. Clin Nurs Stud 3(3):96-104. https://doi.org/10.5430/cns. v3n3p96

Rajala M, Kaakinen P, Fordell M, Kääriäinen M (2018) The quality of patient education in day surgery by adult patients. J Peri Anesth Nurs 33(2):177-187

Sanchis J, Gich I, Pedersen S (2016) Systematic review of errors in inhaler use: has patient technique improved over time? Chest 150: 394-406 
Schuermans D, Hanon S, Wauters I, Verbanck S, Vandevoorde J, Vanderhelst E (2018) Impact of a single 10 min education session on asthma control as measured by ACT. Respir Med 143:14-17

Winders TA, Wilson AM, Fletcher MJ, McGuinness A, Price DB (2019) A patient-centered description of severe asthma: Patient understanding leading to assessment for a severe asthma referral (pulsar). Patient 12(5):539-549

World Health Organization (2018) Chronic respiratory diseases: Asthma. World Health Organization, Geneva. https://www.who.int/ healthtopics/chronic-respiratory-diseases\#tab=tab_1 (accessed 28 December 2019)
All authors contributed to the study conception and design. Material preparation, data collection and analysis were performed by Katariina Mäkelä, Kirsi Kivelä, Pirjo Kaakinen, Maria Kääriäinen, and Mira Rajala. The first draft of the manuscript was written by Katariina Mäkelä, and all authors commented on previous versions of the manuscript. All authors read and approved the final manuscript.

Publisher's note Springer Nature remains neutral with regard to jurisdictional claims in published maps and institutional affiliations. 